\title{
Managing risk of hepatitis $B$ after sharps injuries
}

\author{
Antoon A De Schryver occupational physician, professor, Wim Van Hooste occupational physician, \\ Hilde Van Acker occupational physician, Bieke Claessens occupational physician, Roger Haenen \\ infection control nurse, Katrien Van Crombrugge occupational physician, Lode Godderis occupational \\ physician, professor
}

IDEWE Occupational Health Services, Interleuvenlaan 58, B 3001 Leuven, Belgium

\begin{abstract}
Although Riddell and colleagues' timely update on managing sharps injuries is of great practical use, we have a couple of questions about the hepatitis B management algorithm based on the recipient's vaccination history. ${ }^{1}$

The algorithm, based on UK immunisation guidelines, mentions two possible hepatitis B vaccination histories, one of which is two or more doses of vaccine. Does this mean that people who have received two or more doses are considered to be completely vaccinated and that immunisation of healthcare workers against hepatitis B should be restricted to two doses? This seems contrary to the European consensus of 2000, which recommends three doses as a primary course. ${ }^{2}$

Secondly, the recommendation is to consider a booster vaccine dose in known vaccine responders (anti-hepatitis B surface antigen $>10 \mathrm{mIU} / \mathrm{mL}$ ) who have received two or more doses of vaccine. Does it mean that known vaccine responders who have received three (or more) doses should be given a booster dose?
\end{abstract}

This also seems contrary to the European Consensus, which recommends no booster if the primary vaccination has been effective. ${ }^{2}$ It is also not recommended by various European, ${ }^{3}$ $\mathrm{US}^{4}{ }^{4}$ and other national guidelines. ${ }^{5}$

Competing interests: None declared.

1 Riddell A, Kennedy I, Tong CYW. Management of sharps injuries in the healthcare setting. BMJ 2015;351:h3733. (29 July.)

2 European Consensus Group on Hepatitis B immunity. Are booster immunisations needed for lifelong hepatitis B immunity? Lancet 2000;355:561-5.

3 Puro V, De Carli G, Cicalini S, et al. European recommendations for the management of healthcare workers occupationally exposed to hepatitis $B$ virus and hepatitis $C$ virus. Eurosurveillance 2005;10:260

4 CDC. CDC guidance for evaluating health-care personnel for hepatitis $B$ virus protection and for administering postexposure management. MMWR Rec Rep 2013;62(RR-10):1-19.

5 De Schryver A, Claesen B, Meheus A, et al. European survey of hepatitis B vaccination policies for healthcare workers. Eur J Public Health 2011;21:338-43.

Cite this as: BMJ 2015;351:h5568

๑ BMJ Publishing Group Ltd 2015 